\title{
Construction and Standardization a Students' Academic Skills Assessment Scale for a University of Medical Sciences
}

\author{
Somayeh Shabani ${ }^{1 *}$, Soheila Saraee ${ }^{1}$ and Robert Pasnak ${ }^{2}$ \\ ${ }^{1}$ University of Rudehen, Rudehen, Damavand County, Tehran Province, Iran \\ ${ }^{2}$ George Mason University, Fairfax, Virginia 22030 USA
}

\begin{abstract}
Background: Studies show that many academic skills can affect the academic achievement of medical students, but research in this area usually examines each of the academic skills separately. Because of the importance of these skills, a precise measurement tool is required.

Purpose: The present study was conducted with the aim of constructing an assessment scale for students' academic skills. The theoretical foundations of this study included theories of learning approaches and of self-directed and self-regulated learning strategies. Based on these theories, primary types of academic skills were identified. Psychometric properties were calculated, including content validity, construct validity based on exploratory and confirmatory factor analysis, and reliability based on Cronbach's alpha coefficient.
\end{abstract}

Method: From among the population of 13381 students who were studying at the University of Medical Sciences in the year 2018,225 females and 194 males) were selected through multi-stage random sampling from students studying Medicine, Dentistry, Pharmacy and Nursing.

Findings: The content validity of items was reviewed by experts. The reliability coefficient of the test was calculated, yielding a Cronbach's alpha of 0.913 . Through exploratory factor analysis, 14 factors were identified and named. Confirmatory factor analysis indicators also demonstrated that the model fits the data.

Conclusion: In general, research findings indicate that the academic skills questionnaire has a desirable fit for students and can be used as a valid tool in assessing the students' academic skills.

\section{Introduction}

"Learning how to think or how to learn should become an important principle in educational systems" [1]. In higher education systems, one of the important necessities is the expansion and strengthening of academic skills among students. Currently, the task of educational systems or universities is not direct intervention in learning and transfer of information to learners, but the educational system is based on providing learning experiences, learning activities and teaching how to think [2].

Students may spend a lot of time on studying and reading lessons, but often their reading is not worthwhile. In fact, many learners have not learned the rules of learning but should learn them. Many other students may, without knowing it themselves, use the correct method of study and learning. The important point is that this basically correct but unknowing and unguided behavior does not always lead to improvement in speed, quality and accuracy of learning. In contrast, students with targeted programs can guide their performance in the right direction. A lack of attention to such programs and to educational and learning skills of students in the educational system can cause decrease of student's academic motivation and academic failure [3].

Medical students are also confronted with a huge number of textbooks at the start of their university training and spend a lot of time learning this material, but they are not satisfied with their academic achievement. Many psychologists have found that the failure of many students to study is not due to their poor mental ability, but rather that they do not know how to study, or, in other words, that they do not have enough information about learning and study skills [4].

When they go to college many students have little information in terms of essential skills at the university, among which are studying and learning skills. Students should be able to evaluate the impact of using these skills in the university and use them according to their outcomes [5]. Study and learning strategies are a systematic process that is used by learners to provide a deep and comprehensive understanding of content, and includes the application of some behaviors, thoughts and actions in the learning process with the aim of obtaining more information, storing new knowledge in memory and improving skills [6]. These strategies include attitude, time management, motivation, anxiety, focus, study guidance, test strategies, self-examination and the choice of main ideas [7].

Several studies have been carried out in this regard. The results of Nouhi, Shakoori, and Nakhei [8] in Kerman University of Medical Sciences showed that students who have poor study habits and skills also

${ }^{\star}$ Correspondence to: Somayeh Shabani, University of Rudehen, Rudehen, Damavand County, Tehran Province, Iran, Tel: +98-912-4224408; E-mail: shabani.somayeh@gmail.com

Key words: academic skills, standardization, validating, reliability, medical sciences

Received: July 29, 2020; Accepted: August 13, 2020; Published: August 19, 2020 
have difficulty in managing time, planning, taking notes and focusing on studying [4]. Sullivan [9] also states that research has shown programs that emphasize teaching methods or pervasive learning behaviors are more likely to improve the educational status of learners than programs that focus on textbooks or educational technology. Chen [10] suggested that the amount of readiness, motivation, past experiences, learning environment and teaching method of the teacher were all effective.

Many studies indicate that students who were less well-informed about study and learning strategies than other students, and who did not know the strategies of studying had more problems about how to apply the information they learned, as well as problems in successive academic stages [11].

Based on such research findings, it seems that the difference between many students with high and low grades is due to their different learning skills and study methods, and that what causes these differences between individuals is their particular study and learning methods. Therefore, it seems that for more students to have good performances at the university level, they must use different academic skills and learning strategies.

Academic skills help learners to handle different learning situations more efficiently and effectively, in such a way that new information is acquired, maintained, and will be used in future learning. Although academic skills are considered important in learning, Woolfolk [12] observed that regular academic skills training is not implemented in many schools. Biabangard [13] said that because academic skills training is not part of a common curriculum, teachers need to emphasize the importance of academic skills and use of information methods that can launch independent learning. A proper study method can solve many problems in study and learning. Research by Boehler et al. [14] suggests that success can be predicted through student learning approaches that include reading skills and study habits.

In the last few years, information processing has come to be considered one of the important learning theories. Based on this theory, there are strategies that can be used to facilitate learning [15]. Skills or study strategies include the hidden behaviors and obvious thoughts that are relevant to learning success and can be changed through academic interventions. These skills or strategies are defined as any cognitive, emotional or behavioral activity that facilitates the process of storing, retrieving and using knowledge or learnings [16]. Cognitive strategies refer to any kind of behavior, thought or action that aims to help learning, organizing, and storing knowledge and make it easier to use them in the future. The emotional components of the study process include inhibiting anxiety and avoidance, which are related to procrastination or neglect, and behavioral factors include taking notes, highlighting information and reconsidering [17].

Metacognitive strategies are regulatory and used in monitoring cognitive strategies and guidance. Self-regulation in learning is one of the processes that deal with the role of the individual. The importance of this self-regulation in successful academic, occupational learning is so great that different scholars have presented different models of it. One of these is that of Pintrich and De Groot [18]. In this model, self-regulated learning is used to optimize the use of cognitive, metacognitive and resource management strategies to maximize learning.

Self-regulated strategies can be divided into three categories: planning strategies, monitoring and control strategies, and regulation strategies. Resource management strategies are facilitating strategies, and learners typically use them to control and manage the environment, such as management in organizing resources, time, how to try, choosing a study environment, and helping other people, such as teachers or peers [18]. Hence, the theory of self-regulated learning is based on how learners organize their learning through meta-cognitive, motivational, and behavioral means.

Independently, Berger and Karabenick [19] concluded that there is a meaningful relationship between self-regulation, learning strategies and motivation. In other words, the successful application of selfregulated strategies, such as "repetition" and "organizing", leads to an increase in self-efficacy beliefs, and therefore students' engagement in learning lessons increases. The model of Fenollar, Roman and Cuestas [20] confirmed and emphasized the important mediatory role of study strategies in influencing the goals of progress and self-efficacy on academic performance.

Durak, Torun, Sayiner, \& Kandiloglu [21] also reported that many students suffer from frustration and academic failure due to a lack of study and learning skills. Learning and study strategies improve their performance by facilitating the students' learning process. Learning and study strategies are like a tool that can help students solve academic problems and grow the skills they need during their school years. Identifying and reinforcing these skills helps students to successfully complete college education by using their natural abilities effectively. The results of several studies [22-27], illustrate that in order to achieve proper development and function in education, a person must have readily available study skills and habits to use and access knowledge, and that good students are those who are more aware of their activities and show greater persistence toward their goals. Studies on the relationship between academic performance and study habits have concluded that good reading habits have a positive relationship with academic performance. That is, a person with good habits will perform better.

Shih, Chiang, Lai, and Huc [28] standardized a scale of learning and study strategies for Taiwanese students. They found that among the test domains the lowest scores were for main idea selection, attitude and motivation. Gordon's [29] study indicated that students who did not fail in their academic semesters better understood the main idea of lessons, had less anxiety, were more successful in information processing, and used more self-testing and testing strategies than other students.

Zhou, Graham, and West [30] also conducted a study of the relationship between study strategies and academic performance. The study was conducted to determine whether the LASSI Strategy for Learning and Study Strategies and the Self-Learning Scale (SDLRS) were predictive of academic performance. The results showed that SDLRS was moderately correlated with all LASSI subscales. However, the predictive value of these two questionnaires is different. The SDLRS scale is not directly related to academic performance, but the LASSI subscales such as focus, motivation, time management, and test strategies are related. The results of this study indicate that the use of LASSI for medical school students provides information about their strengths and weaknesses, underpinning the implementation of specific study strategies and positive academic performance

Moghadam and Cheraghian [31] examined the study strategies of Abadan nursing students and concluded that their strategies had a moderate but positive and significant relationship to their academic performance. Nourian et al. [32] concluded that most students had difficulty in managing time, taking notes, focusing and comprehension.

Yip [33] found that there were clear differences between the study strategies of students who had academic success and other students. 
Attitude and motivation were also important factors that distinguished successful students from unsuccessful ones. Yip [33] finally concluded that it was possible and desirable to change study and learning strategies of students through academic interventions.

In general, studies have shown that many academic skills contribute to academic achievement, but research in this area usually examines each academic skill separately. In no research have all components of academic skills been investigated and there is no standard and unitary questionnaire available. For example, a questionnaire with 52 items to measure self-directed learning readiness was created by Fisher, King and Tague [34]. An analysis of primary components or varimax rotation was used to determine the basis of factor analysis of tool items, Eventually, a 40-point Fisher's Self-Directed Learning Readiness Scale (SDLRS) resulted which yielded the three basic elements of self-management, willingness to learn and self-control [35]. Hendry and Ginns [36,37] in another study examined the construct and factor validity of the SDLRS for medical students by using exploratory factor analysis. The data from this research fit a four-factor model. Also, Cadorin, Bressan and Palese examined instruments for evaluating self-directed learning abilities among nursing students and nurses. They evaluated 11 studies that were based on four scales that were derived from Knowles' theory: 1) the Self-Directed Learning Readiness Scale; 2) the Self-Directed Learning Readiness Scale for Nursing Education; 3) the Self-Rating Scale of Self-Directed Learning, and 4) the Self-Directed Learning Instrument. A few psychometric properties were measured in each of the 11 studies, from two to four out of the ten required. The quality of the methodologies used ranged from fair to poor with the exception of one instrument (the Self-Directed-Learning-Instrument). The psychometric proprieties that emerged across the tools were good in general and Cronbach's a ranged from 0.73 to 0.91 . Structural validity measures showed good indexes both in explorative and confirmative factor analyses.

Borjalilu, Mojtahedzadeh and Mohammadi [38], investigated the factorial structure and validity of a Persian version of a self-regulation questionnaire for medical students. Four factors of planning, selfexamination, effort and self-efficacy were extracted, which explained 55 per cent of the total variance in self-regulation. In another study [39], developed a tool for measuring study and learning strategies. The questionnaire of 86 questions was based on an information processing approach. Its psychometric properties (retest validity 0.98 , Cronbach's alpha, 0.98 ) were validated and its factorial validity was confirmed.

Behar-Horenstein, Beck and Su [40] conducted an initial validation of the Self-Rating Scale of Self-Directed Learning for Pharmacy Education. The purpose of this study was to explore and validate the factor structure of the original SRSSDL scale with pharmacy students. Five factors - intrinsic motivation, awareness, collaboration, application and reflection - showed acceptable levels of reliability. Hence, the revised 55-item SRSSDL was a valid and homogenous scale of pharmacy students' self-directed learning within one pharmacy program.

In yet another study, Talebi and Abedi [41] developed and validated an academic motivation scale for students. The results showed that academic motivation consisted of seven factors. Four factors (academic self-efficacy, achievement motivation, positive self-concept and internal motivation for gaining knowledge) related to internal motivation and other three factors (educational environment, social, and economic) referred to external motivation. The result also indicated that this scale has satisfactory validity and reliability.
Taken together, the research studies indicate that one of the factors in increasing academic failure in medical science universities is low awareness and lack of appropriate academic skills among students. Therefore, the present study was designed to construct and standardize a valid instrument for measuring students' academic skills.

Hence, the main issues facing this research are:

1- What are the main components of academic skills as measured by a questionnaire based on research?

2- How valid is the questionnaire made on this basis?

3- To what degree does the questionnaire on academic skills have internal consistency?

4- What kind of factor structure does the questionnaire have?

\section{Method}

The present research method is descriptive-analytic. Descriptive indices and reliability, validity and factor structure analysis were used to estimate the psychometric properties of the academic skill scale.

\section{Statistical population, sample and sampling method}

The potential population of this study was 13381 students of the University of Medical Sciences in the academic year of 2018. Klein considers samples larger than 200 as "great examples" and believes that it is suitable for many models. In addition, according to Hooman [42,43], 15 people are logically needed for each variable measured. Therefore, 419 students were selected via randomized multi-stage sampling from the University of Medical Sciences, Faculty of Medicine, Dentistry, Pharmacy and Nursing. In the next step, students from each faculty (program) responded to the academic skills questionnaire. For the sample, $53.7 \%$ were female and $46.3 \%$ were male, $57.5 \%$ were in bachelor's degree programs, $8.3 \%$ in Master's degree programs and $34.2 \%$ were in Ph.D. programs.

\section{Measuring instrument}

The main objective of this research was to develop a valid and reliable tool for measuring academic skills among students of the University of Medical Sciences. To make the tool, the following actions were taken.

First stage: At this stage, psychological and educational texts especially referring to theories of learning approaches, self-regulated learning strategies and self-directed learning theory and definitions were examined. The characteristics, behavioral features, and cognitive skills related to each aspect of academic skills were extracted.

Second stage: A psychological skills scale table based on existing theories was constructed (Table 1).

Third stage: At this stage, questions were prepared and tested so that different dimensions of students skills based on the components above could be carefully measured. The test questions were based on the four existing theories cited in Table 1.

Fourth stage: In order to determine content validity, after reviewing and editing questions, the test was submitted to ten professors and experts in this field. Some of the questions were deleted with their suggestions. Finally, the test was designed in such a way that the various dimensions of academic skills would be in accordance with the existing theories. Questions were created that were to be answered according to a five option Likert scale (I agree, fully agree, no idea, disagree, and completely disagree). 
Table 1. Dimensions of academic skills based on existing theories

Learning approaches based on the Marton and Saljo model completed by Entwistle

\begin{tabular}{|c|c|}
\hline \multicolumn{2}{|c|}{ Learning approaches based on the Marton and Saljo model completed by Entwistle } \\
\hline \multirow{4}{*}{ Deep approach } & Search for meaning \\
\hline & Connection between ideas (connecting ideas and concepts to each other) \\
\hline & Use of evidence \\
\hline & Interested in studied topics \\
\hline \multicolumn{2}{|c|}{ Self-regulated learning strategies based on the Pintrich model } \\
\hline \multirow{3}{*}{ Cognitive } & Repetition and review strategies \\
\hline & Expansion or Semantic expansion strategies \\
\hline & Organization strategies \\
\hline \multirow{3}{*}{ Metacognitive } & Planning strategies \\
\hline & Monitoring and evaluation \\
\hline & Self-directed strategies \\
\hline \multirow{4}{*}{ Resource management } & Time management \\
\hline & Organizing the learning environment \\
\hline & Set up efforts \\
\hline & Seek help \\
\hline \multicolumn{2}{|c|}{ Self-regulated learning strategies based on biological function theory and the general context of the learning approach } \\
\hline \multirow{4}{*}{ External regulated stimuli (sensory stimuli) including teachers, professors and books } & Anxiety \\
\hline & Attitude \\
\hline & Focus \\
\hline & Information processing \\
\hline \multirow{3}{*}{$\begin{array}{l}\text { Mental actions or personal settings (active self-regulated process) including control thinking } \\
\text { of learner }\end{array}$} & Motivation \\
\hline & Self-examination \\
\hline & Choosing the main idea \\
\hline \multirow{3}{*}{$\begin{array}{l}\text { Dynamic brain activity and regulation of subsystems (dynamic self-regulated process) } \\
\text { internal resources and what is controlled by the individual. }\end{array}$} & Study guide \\
\hline & Time management \\
\hline & Test strategies \\
\hline \multicolumn{2}{|c|}{ Self-directed learning } \\
\hline \multirow{4}{*}{ Components of learning and teaching activity } & Creativity \\
\hline & Control \\
\hline & $\begin{array}{l}\text { Learning strategies (the various strategies that students need to make during their learning } \\
\text { process in order to become self-regulated) }\end{array}$ \\
\hline & $\begin{array}{l}\text { Learning activities (identify the necessary activities for becoming self-directed in learning } \\
\text { process) }\end{array}$ \\
\hline \multirow{5}{*}{ Components of learner features } & Self-efficacy \\
\hline & Motivation \\
\hline & Awareness (related to students' perceptions of factors helping to become self-directed) \\
\hline & Evaluation (identify specific characteristics of students that monitor their learning activities) \\
\hline & $\begin{array}{l}\text { Interpersonal or social skills (students' skills in interpersonal relationships that are } \\
\text { prerequisites of becoming self-directed) }\end{array}$ \\
\hline
\end{tabular}

\section{Implementation method}

A preliminary questionnaire with 131 questions for 14 components was distributed among 50 students and 42 questionnaires (21 females and 21 males) were collected and analyzed. For the questionnaire with 131 questions, Cronbach's alpha was 0.89 . Then the loop method was implemented. This method eliminates the alpha amount of each item and calculates the overall alpha without them. Whenever alpha is reduced by eliminating the question, the value and contribution of the question is apparent in overall alpha. On the contrary, if alpha is increased by eliminating the question, the question's value is low. Therefore, the loop method keeps a question that, with its deletion, alpha decreases, but eliminates questions whose elimination increases alpha. After this process, 27 questions were removed and 104 questions remained. The Cronbach's alpha of the resulting questionnaire reached 0.91 .

The remaining 104 questions were distributed in terms of content in 14 sub-tests as described in Table 2.

\section{Main procedure}

After evaluating the 104 remaining questions, they were distributed to 500 students from the medical, dental, pharmacy and nursing faculties. Out of the 500 distributed questionnaires, 419 were collected and processed. Questions again required response in terms of the five degrees Likert scale ranging from fully agree to completely disagree. Samples were selected from

\section{Data analysis method}

All statistical operations were performed using the spss22 and Lisrel 8.5 software. To determine the final questions of the questionnaire, the correlation coefficient of each question with the whole test was used. To assess the content validity, only professors were polled. Factor analysis and confirmatory factor analysis were used to investigate the questionnaires construct validity. The internal consistency according Cronbach's alpha was used to assess reliability. 


\section{Findings}

In order to validate the construct validity of this questionnaire and answer the question of whether the questionnaire was really measuring what it was designed for, an exploratory factor analysis was performed. The principal components were analyzed to indicate what factors underpinned the questionnaire.

To determine if the sample size was sufficient for factor analysis, the Kaiser-Meyer- Olkin measure of sampling adequacy test was performed. Bartlett's test of sphericity was used to determine that the correlation between test materials in the community is not zero, Since the questionnaire has 14 subtests, the results for each sub-test are given in Table 3.

As shown in this table, the KMO test size for all scales is higher than 0.6 , indicating that the correlation matrix has sufficiency. The significance level of the Bartlett test is also less than 0.05 at all scales, so zero being the unit of the correlation matrix is rejected.

In the factor analysis of academic skills test questions, 14 factors were obtained that have the most meaning (Table 4).
Factor loadings for each of the factors of the academic skills test are given in Table 5.

To verify the validity of the above construct analysis, a confirmatory factor analysis was performed with version 8.5 of the LISREL software. The method of maximum likelihood was used. The fit index for the academic skills assessment scale are presented in Table 6 .

The ratio index of $\chi 2$ to degrees of freedom confirms the fit of the model. Df $/ 2 \chi$ is equal to $1 / 87$, This number is less than 3 , which means the data fit the model. Since chi-squared is influenced by sample size and the number of structural model relationships [44], so another fit models should also be used [45]. The RMSEA error is 0.048 and the square root of remaining squares (SRMR) is 0.066 which is smaller than the criterion (0.08) and therefore confirms the fit of the model. Finally, the IFI, CFI, and NNFI indexes are also larger than the desired criteria (0.9) and confirm the fit of the model.

In Table 7 , the results of factor loadings related to questions of academic skills questionnaire in the state of standard and nonstandard coefficients are presented separately for each of components.

Table 2. Dimensions of academic skills scale with questions number

\begin{tabular}{|c|c|c|c|c|}
\hline Component & Number & $\begin{array}{c}\text { Number of } \\
\text { items }\end{array}$ & Component & Number \\
items
\end{tabular}

Table 3. KMO-related measurements and Bartlett tests of sphericity for 14 sub-tests of the academic skills questionnaire

\begin{tabular}{|c|c|c|c|c|}
\hline Component & KMO & Chi-square & Degrees of freedom & Significance \\
\hline Active learning & 0.780 & 313.281 & 15 & 0.001 \\
\hline Information processing & 0.750 & 263.386 & 21 & 0.001 \\
\hline Learning activities & 0.661 & 155.762 & 15 & 0.001 \\
\hline Organization strategies & 0.782 & 242.927 & 15 & 0.001 \\
\hline Control over learning activity & 0.734 & 571.017 & 120 & 0.001 \\
\hline Monitoring and evaluation & 0.770 & 228.885 & 36 & 0.001 \\
\hline Anxiety & 0.770 & 228.885 & 36 & 0.001 \\
\hline Resource management & $0 / 741$ & $412 / 928$ & 55 & 0.001 \\
\hline Focus & 0.607 & 55.84 & 6 & 0.001 \\
\hline Choose the main idea & $0 / 602$ & $42 / 778$ & 6 & 0.001 \\
\hline Creativity & 0.684 & 39.563 & 6 & 0.001 \\
\hline Interpersonal social skills & $0 / 809$ & $409 / 418$ & 55 & $0 / 001$ \\
\hline Self-efficacy & 0.788 & 314.270 & 36 & 0.001 \\
\hline Learning motivation & 0.696 & 201.779 & 21 & 0.001 \\
\hline
\end{tabular}

Table 4. Factors and questions are related to each factor

\begin{tabular}{|c|c|c|c|c|c|}
\hline Component & Number & Number of deleted items & Component & Number & $\begin{array}{l}\text { Number of } \\
\text { deleted items }\end{array}$ \\
\hline Active learning & $2,17,19,36,37,50$ & 0 & Resource management & $\begin{array}{c}8,24,42,56,68,78,87 \\
90,70\end{array}$ & 2 \\
\hline Information processing & $1,11,18,44,27,69,103$ & 0 & Focus & $10,26,79$ & 1 \\
\hline Learning activities & $3,38,51,62,72,83$ & 0 & Choose the main idea & 28,45 & 2 \\
\hline Organization strategies & $4,20,29,39,66,52$ & 0 & Creativity & $12,31,35,104$ & 0 \\
\hline $\begin{array}{c}\text { Control over learning } \\
\text { activity }\end{array}$ & $5,7,21,40,53,55,76,82,86,94,96,97,98,99$ & 2 & Interpersonal social skills & $\begin{array}{c}13,16,49,65,61,71,75 \\
81,88,91\end{array}$ & 1 \\
\hline Monitoring and evaluation & $41,54,67,77,89,92,95,6$ & 1 & Self-efficacy & $46,63,15,34,48,64,74,100$ & 1 \\
\hline Anxiety & $9,25,43$ & 1 & Learning motivation & $80,84,93,47,14$ & 2 \\
\hline
\end{tabular}


Table 5. Factor loadings of items of academic skills test

\begin{tabular}{|c|c|c|c|c|c|c|c|c|c|c|c|c|c|c|}
\hline & & & & & & & Com & ents & & & & & & \\
\hline Items & 1 & 2 & 3 & 4 & 5 & 6 & 7 & 8 & 9 & 10 & 11 & 12 & 13 & 14 \\
\hline 2 & 0.68 & & & & & & & & & & & & & \\
\hline 17 & 0.66 & & & & & & & & & & & & & \\
\hline 19 & 0.63 & & & & & & & & & & & & & \\
\hline 36 & 0.68 & & & & & & & & & & & & & \\
\hline 37 & 0.71 & & & & & & & & & & & & & \\
\hline 50 & 0.58 & & & & & & & & & & & & & \\
\hline 1 & & 0.61 & & & & & & & & & & & & \\
\hline 11 & & 0.63 & & & & & & & & & & & & \\
\hline 18 & & 0.61 & & & & & & & & & & & & \\
\hline 27 & & 0.63 & & & & & & & & & & & & \\
\hline 44 & & 0.59 & & & & & & & & & & & & \\
\hline 69 & & 0.53 & & & & & & & & & & & & \\
\hline 103 & & 0.51 & & & & & & & & & & & & \\
\hline 3 & & & 0.45 & & & & & & & & & & & \\
\hline 38 & & & 0.61 & & & & & & & & & & & \\
\hline 51 & & & 0.67 & & & & & & & & & & & \\
\hline 62 & & & 0.66 & & & & & & & & & & & \\
\hline 72 & & & 0.59 & & & & & & & & & & & \\
\hline 83 & & & 0.42 & & & & & & & & & & & \\
\hline 4 & & & & 0.61 & & & & & & & & & & \\
\hline 20 & & & & 0.50 & & & & & & & & & & \\
\hline 29 & & & & 0.57 & & & & & & & & & & \\
\hline 39 & & & & 0.63 & & & & & & & & & & \\
\hline 52 & & & & 0.72 & & & & & & & & & & \\
\hline 66 & & & & 0.71 & & & & & & & & & & \\
\hline 5 & & & & & 0.57 & & & & & & & & & \\
\hline 7 & & & & & 0.22 & & & & & & & & & \\
\hline 21 & & & & & -0.10 & & & & & & & & & \\
\hline 23 & & & & & 0.32 & & & & & & & & & \\
\hline 40 & & & & & 0.53 & & & & & & & & & \\
\hline 53 & & & & & 0.60 & & & & & & & & & \\
\hline 55 & & & & & 0.55 & & & & & & & & & \\
\hline 76 & & & & & 0.44 & & & & & & & & & \\
\hline 82 & & & & & 0.46 & & & & & & & & & \\
\hline 86 & & & & & 0.55 & & & & & & & & & \\
\hline 94 & & & & & 0.25 & & & & & & & & & \\
\hline 96 & & & & & 0.43 & & & & & & & & & \\
\hline 97 & & & & & 0.30 & & & & & & & & & \\
\hline 98 & & & & & 0.51 & & & & & & & & & \\
\hline 99 & & & & & 0.57 & & & & & & & & & \\
\hline 101 & & & & & 0.18 & & & & & & & & & \\
\hline 6 & & & & & & 0.71 & & & & & & & & \\
\hline 22 & & & & & & 0.08 & & & & & & & & \\
\hline 41 & & & & & & 0.47 & & & & & & & & \\
\hline 54 & & & & & & 0.56 & & & & & & & & \\
\hline 67 & & & & & & 0.52 & & & & & & & & \\
\hline 77 & & & & & & 0.55 & & & & & & & & \\
\hline 89 & & & & & & 0.60 & & & & & & & & \\
\hline 92 & & & & & & 0.40 & & & & & & & & \\
\hline 95 & & & & & & 0.47 & & & & & & & & \\
\hline 9 & & & & & & & 0.77 & & & & & & & \\
\hline 25 & & & & & & & 0.77 & & & & & & & \\
\hline 43 & & & & & & & 0.48 & & & & & & & \\
\hline 57 & & & & & & & -0.04 & & & & & & & \\
\hline 8 & & & & & & & & 0.53 & & & & & & \\
\hline 24 & & & & & & & & 0.48 & & & & & & \\
\hline 30 & & & & & & & & 0.14 & & & & & & \\
\hline
\end{tabular}




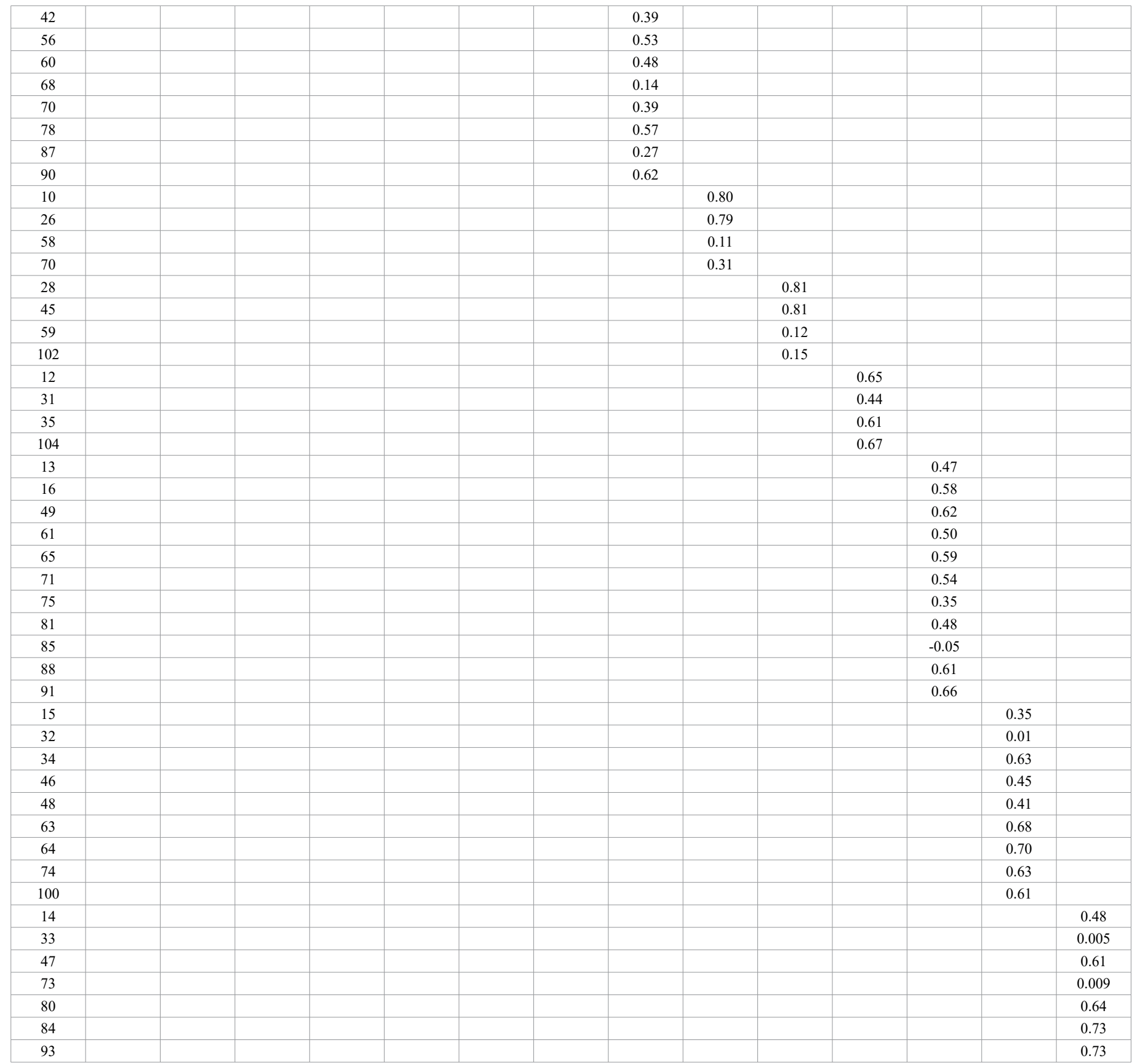

Table 6. Fit index of academic skills scale

\begin{tabular}{|c|c|c|c|}
\hline Fit indicator & Acceptable domain & Observed value \\
\hline $\mathrm{X}^{2} / \mathrm{df}$ & $\leq 3$ & 1.87 & 0.93 \\
IFI & $>0 / 9$ & 0.93 & Fit index assessment \\
NNFI & $>0 / 9$ & 0.048 & Fit \\
RMSEA & $<0 / 08$ & 0.93 & Fit \\
CFI & $>0 / 9$ & 0.066 & Fit \\
SRMR & $<0 / 08$ & Fit & \\
\hline
\end{tabular}


Table 7. Factor loadings of questions of the academic skills questionnaire in confirmatory factor analysis

\begin{tabular}{|c|c|c|c|c|}
\hline Component & Question & Non-standard coefficient & Standard coefficient & Test statistic \\
\hline \multirow{6}{*}{ Active learning } & 2 & 0.57 & 0.54 & 11.31 \\
\hline & 17 & 0.59 & 0.54 & 11.27 \\
\hline & 19 & 0.53 & 0.51 & 10.51 \\
\hline & 36 & 0.61 & 0.58 & 12.24 \\
\hline & 37 & 0.58 & 0.54 & 11.42 \\
\hline & 50 & 0.52 & 0.53 & 11.10 \\
\hline \multirow{7}{*}{ Information processing } & 1 & 0.49 & 0.48 & 10.16 \\
\hline & 11 & 0.46 & 0.44 & 9.12 \\
\hline & 18 & 0.55 & 0.52 & 11 \\
\hline & 27 & 0.51 & 0.49 & 9.91 \\
\hline & 44 & 0.50 & 0.47 & 9.78 \\
\hline & 69 & 0.40 & 0.40 & 8.36 \\
\hline & 103 & 0.39 & 0.37 & 7.72 \\
\hline \multirow{6}{*}{ Learning activities } & 3 & 0.42 & 0.41 & 8.37 \\
\hline & 38 & 0.45 & 0.43 & 8.75 \\
\hline & 51 & 0.48 & 0.48 & 9.94 \\
\hline & 62 & 0.43 & 0.41 & 8.41 \\
\hline & 72 & 0.46 & 0.44 & 9.01 \\
\hline & 83 & 0.40 & 0.35 & 7.24 \\
\hline \multirow{6}{*}{ Organization strategies } & 4 & 0.46 & 0.40 & 7.98 \\
\hline & 20 & 0.48 & 0.40 & 8.09 \\
\hline & 29 & 0.46 & 0.42 & 8.58 \\
\hline & 39 & 0.47 & 0.42 & 8.46 \\
\hline & 52 & 0.57 & 0.55 & 11.31 \\
\hline & 66 & 0.56 & 0.54 & 11.21 \\
\hline \multirow{14}{*}{ Control over learning activity } & 5 & 0.52 & 0.47 & 10.04 \\
\hline & 7 & 0.42 & 0.43 & 8.74 \\
\hline & 23 & 0.46 & 0.42 & 8.92 \\
\hline & 40 & 055 & 0.53 & $32 / 11$ \\
\hline & 53 & 0.47 & 0.45 & 9.67 \\
\hline & 55 & 0.35 & 0.33 & 6.95 \\
\hline & 76 & 0.33 & 0.31 & 6.42 \\
\hline & 82 & 0.34 & 0.33 & 6.90 \\
\hline & 86 & 0.37 & 0.35 & 7.41 \\
\hline & 94 & 0.38 & 0.38 & 8.03 \\
\hline & 96 & 0.52 & 0.47 & 10.04 \\
\hline & 97 & 0.42 & 0.43 & 8.74 \\
\hline & 98 & 0.46 & 0.42 & 8.92 \\
\hline & 99 & 0.55 & 0.53 & 11.32 \\
\hline \multirow{8}{*}{ Monitoring and evaluation } & 6 & 0.63 & 0.57 & 12.21 \\
\hline & 41 & 0.43 & 0.37 & 7.70 \\
\hline & 54 & 0.54 & 0.49 & 10.42 \\
\hline & 67 & 0.61 & 0.58 & 12.56 \\
\hline & 77 & 0.34 & 0.33 & 6.83 \\
\hline & 89 & 0.57 & 0.53 & 11.30 \\
\hline & 92 & 0.48 & 0.43 & 8.94 \\
\hline & 95 & 0.36 & 0.34 & 6.92 \\
\hline \multirow{4}{*}{ Anxiety } & 9 & 0.40 & 0.38 & 7.40 \\
\hline & 25 & 0.44 & 0.42 & 7.74 \\
\hline & 43 & 0.56 & 0.50 & 8.88 \\
\hline & 57 & 0.52 & 0.51 & 8.90 \\
\hline \multirow{9}{*}{ Resource management } & 8 & 0.40 & 0.40 & 8.31 \\
\hline & 24 & 0.42 & 0.41 & 8.58 \\
\hline & 42 & 0.46 & 0.41 & 8.70 \\
\hline & 56 & 0.53 & 0.50 & 10.76 \\
\hline & 68 & 0.45 & 0.43 & 8.97 \\
\hline & 70 & 0.45 & 0.43 & 9.16 \\
\hline & 78 & 0.40 & 0.41 & 8.67 \\
\hline & 87 & 0.48 & 0.46 & 9.86 \\
\hline & 90 & 0.54 & 0.48 & 10.33 \\
\hline
\end{tabular}




\begin{tabular}{|c|c|c|c|c|}
\hline \multirow{3}{*}{ Focus } & 10 & 0.46 & 0.40 & 5.34 \\
\hline & 26 & 0.93 & 0.79 & 6.45 \\
\hline & 79 & 0.38 & 0.37 & 4.62 \\
\hline \multirow{3}{*}{ Choose main idea } & 28 & 0.73 & 0.65 & 9.36 \\
\hline & 45 & 0.62 & 0.52 & 8.31 \\
\hline & 59 & 0.45 & 0.43 & 6.17 \\
\hline \multirow{3}{*}{ Creativity } & 12 & 0.47 & 0.44 & 7.15 \\
\hline & 35 & 0.48 & 0.45 & 7.20 \\
\hline & 104 & 0.41 & 0.38 & 6.58 \\
\hline \multirow{9}{*}{ Interpersonal social skills } & 13 & 0.39 & 0.34 & 7.06 \\
\hline & 16 & 0.48 & 0.48 & 10.22 \\
\hline & 49 & 0.40 & 0.44 & 9.31 \\
\hline & 61 & 0.41 & 0.37 & 7.56 \\
\hline & 65 & 0.56 & 0.53 & 11.51 \\
\hline & 71 & 0.43 & 0.38 & 7.97 \\
\hline & 75 & 0.50 & 0.48 & 10.34 \\
\hline & 88 & 0.53 & 0.49 & 10.56 \\
\hline & 91 & 0.53 & 0.48 & 10.43 \\
\hline \multirow{8}{*}{ Self-efficacy } & 15 & 0.37 & 0.35 & 7.15 \\
\hline & 34 & 0.47 & 0.47 & 9.64 \\
\hline & 46 & 0.37 & 0.36 & 7.15 \\
\hline & 48 & 0.30 & 0.31 & 6.26 \\
\hline & 63 & 0.39 & 0.39 & 7.88 \\
\hline & 64 & 0.50 & 0.49 & 10.14 \\
\hline & 74 & 0.57 & 0.55 & 11.63 \\
\hline & 100 & 0.42 & 0.40 & 8.19 \\
\hline \multirow{5}{*}{ Learning motivation } & 14 & 0.34 & 0.30 & 5.26 \\
\hline & 47 & 0.36 & 0.31 & 5.39 \\
\hline & 80 & 0.53 & 0.48 & 8.15 \\
\hline & 84 & 0.59 & 0.51 & 8.55 \\
\hline & 93 & 0.34 & 0.30 & 5.26 \\
\hline
\end{tabular}

Table 8. Cronbach's alpha coefficients of for the academic skills questionnaire

\begin{tabular}{|c|c|c|c|}
\hline Component & Number of questions & Number of persons & Cronbach's alpha \\
\hline Active learning & 6 & 419 & 0.709 \\
\hline Information processing & 7 & 419 & 0.644 \\
\hline Learning activities & 6 & 419 & 0.563 \\
\hline Organization strategies & 6 & 419 & 0.614 \\
\hline Control over learning activity & 10 & 419 & 0.572 \\
\hline Monitoring and evaluation & 8 & 419 & 0.657 \\
\hline Anxiety & 4 & 419 & 0.391 \\
\hline Resource management & 4 & 419 & 0.682 \\
\hline Focus & 3 & 419 & 0.581 \\
\hline Choose main idea & 3 & 419 & 0.527 \\
\hline Creativity & 3 & 419 & 0.352 \\
\hline Interpersonal social skills & 9 & 419 & 0.654 \\
\hline Self-efficacy & 8 & 419 & 0.614 \\
\hline Learning motivation & 4 & 419 & 0.370 \\
\hline Total & 86 & 419 & 0.913 \\
\hline
\end{tabular}

The t-statistic and significant level related to each of the questions are provided. All factor loadings are significant at the alpha level of 0.01 .

Cronbach's alpha coefficient was used to assess the internal consistency of the academic skills questionnaire. The correlation of each scale with the total score of the same scale was determined. Based on these results, the reliability of the total questionnaire is equal to 0.913 . The reliability of the subscales ranges from 0.35 to 0.71 . The results of Cronbach's alpha coefficient analyses for components and the whole questionnaire are presented in Table 8.

\section{Discussion}

This research was conducted with the aim of constructing a students' academic skills scale. The exploratory factor analysis indicated that some of 104 proposed questions loaded in common factors; they were removed. In the end, 86 questions were identified with factor loadings of more than 0.4 that could explain about 0.44 of the variance in total academic skills scores with 14 factors. The Cronbach's alpha coefficient $(0.913)$ for the student sample confirmed that the scale 
reliability and the internal consistency of the questions is acceptable. Another important result of this study is access to 14 factors in the substructure of academic skills. These factors verify the theoretical and conceptual model of the research.

The construct validity of the scale was verified by analysis. For identifying the coefficients, exploratory and confirmatory factor analysis and LISREL software were used. The chi-square index to degrees of freedom ratio is an absolute fit index [46]. This ratio for the present model is $1 / 87$, which indicates that the model fitted the data. Additionally, the root mean square error of approximation was 0.048 , which indicate a good fit of the model to the data. The comparative fitting index (CFI) was 0.93 , the non-Normed fitting index (NNFI) was 0.93 , and the IFI index was 0.93 , The closer these indicators are to one another, the better fit the model has. The overall results of this study demonstrate that the psychometric variables of validity and reliability are appropriate and that this test can be used to examine student's academic skills.

Several studies have illustrated that many different factors in academic skills affect academic achievement. For example, Fereidouni Moghadam and Cherghian (2009) and Nourian et al. [32] indicated that the study habits of individuals have a positive and significant relationship to their performance. Fenollar, Roman \& Cuestas [20], Hailikari, Nevgi \& Komulainen [47] emphasized the importance of studying strategies on academic performance. In addition, the studies of Di La Fuente and and Cardelle [24,25] indicate a positive relationship between good reading habits and academic performance. Alibakhshi and Zare [17] pointed to the role of knowledge structures, information processing processes, self-regulation, skills and study strategies on academic performance. Miller and Brickman [27], Isariada [26], Einley and Patrick and Einley also showed that in order to progress and function properly in educational settings, each person must have appropriate skills and habits to acquire knowledge and apply it effectively.

Despite the importance of academic skills in academic performance, there has been no unitary tool for assessing these skills. For example, to measure self-directed readiness, a tool has been developed by Fisher, King and Tago, whose factor structure was subsequently confirmed by Nadi and Sajadian [35]. Borjalilu et al. [38], on the other hand, examined the factor structure of self-regulation questionnaires among medical students. In another study, Karami et al. [39] developed a tool for measuring learning strategies based on information processing theory. Durak et al. [21], Shih et al. [28] Gordon [29], Yip [33] also examined different study and learning strategies which might facilitate the learning processes of students. In the present research, for the first time a scale of academic skills was constructed based on the four dominant theories. It has satisfactory psychometric properties. This tool can assess fourteen components of academic skills and, because of its validity and reliability indicators, it can be used to evaluate a wide range of students' academic skills.

\section{Declarations}

The research reported here was supported in part by the Institute of Education Sciences, U.S. Department of Education, through Grant 305A170114 to George Mason University. The opinions expressed are those of the authors and do not represent views of the Institute or the U.S. Department of Education.

\section{References}

1. Shabani H (2014) Educational Skills (Methods \& Teaching Techniques) Tehran: Samt.

2. Ahrari K, Alizadeh S, Alizadeh M (2013) Learning strategies of nursing and midwifery of Arak branch of Azad University. Journal of Medical Education and Development 8: 23-32.

3. Javadi M, Keyvanara M, Yaghoobi M, Hassanzadeh A, Ebadi Z (2010) The relationship between metacognitive awareness of reading strategies and students' academic status in Isfahan university of medical sciences. Iranian Journal of Medical Education 10.

4. Badeleeh M, Hosseini A, Charkazi A, Jafari Y, Bakhsha F (2013) The relationship between students' study skills and academic achievement. Iranian Journal of Medical Education 13

5. Rachal KC, Daigle SH, Rachal WS (2007) Learning problems reported by college students: Are they using learning strategies? Instructional Psychology 34: 191-199.

6. Corkett GK, Parrila R, Hein SF (2006) Learning and study strategies of university students who report a significant history of reading difficult. Development Disabilities Bulletin 34: 57-79.

7. Alzamani MS, Zirak A (2011) Students learning and study strategies in Isfahan University of Medical Sciences and their relationship with test anxiety. Iranian Journal of Medical Education 11.

8. Nouhi E, Shakoori A, Nakhei N (2008) Study habits and skills, and academic achievement of students in Kerman University of medical sciences. Journal of Medicine Education 12: 77-80.

9. Sullivan FR (2009) Risk and responsibility: A self-study of teaching in second life Journal of Interactive Learning Research 20: 337-357.

10. Chen ML (2009) Influence of grade level on perceptual learning style preferences and language learning strategies of Taiwanese English as origin language learners. Learning and Individual Differences 19: 304-308.

11. Hoveland CM (2006) Relationships between learning and study strategies and academic achievement in associate degree nursing students (unpublished dissertation) Laramie Wyoming: University of Wyoming.

12. Woolfolk AE (2001) Educational psychology (8th Ed.) Boston: Allyn and Bacon.

13. Biabangard S (2005) Educational Psychology. Tehran: virayesh.

14. Boehler ML, Schwinn C, Folse R, Dunnington GL, Markwell SJ, et al. (2001) An evaluation of study habits of third-year medical students in a surgical clerkship. The American Journal of Surgery 181: 268-271.

15. Seif AA (2007) Educational Psychology. Tehran: Agah Press.

16. Derossis AM, Rosa D, Schwartz A, Hauge LS, Bordage G (2004) Study habits of surgery residents and performance on American Board of Surgery In-Training examinations. American Journal of Surgery 188: 230-236.

17. Alibakhshi Z, Zare H (2010) Effect of teaching self-regulated learning and study skills on the academic achievement of university students. Journal of Applied Psychology 3: 69-80.

18. Pintrich PR, de Groot EV (1990) Motivational and self-regulated learning components of classroom academic performance. Journal of Educational Psychology 82: 33-40.

19. Berger J, Karabenick S (2010) Motivation and students use of learning strategies: Evidence of unidirectional effects in mathematics classrooms. Learning and Instruction 41: 1-13.

20. Fenollar P, Roman S, Cuestas PJ (2007) University students' academic performance: An integrative conceptual framework and empirical analysis. The British Journal of Educational Psychology 77: 873-891.

21. Durak HI, Torun SF, Sayiner A, Kandiloglu G (2006) The description and evaluation of an innovative Course on learning and study skills for the 1st year medical students. The Tohoku Journal of Experimental Medicine 210: 231-237

22. Ainley M (2006) Connecting with learning: Motivation affect, and cognition in interest processes. Educational Psychology Review 18: 391-402.

23. Ainley M, Patrick L (2006) Measuring self-regulated learning processes through tracking patterns of student interaction with achievement activities. Educational Psychology Review 18: 267-286.

24. De la Fuente J (2004) Recent perspectives in the study of motivation: The theory of goal orientation. Electronic Journal of Research in Educational Psychology 2: 35-62. 
25. De la Fuente J, Cardelle-Elawar M (2009) Research on action-emotion style and study habits: Effects of individual differences on learning and academic performance of undergraduate students. Learning and Individual Differences 19: 567-576.

26. Isarida T (2005) Study-time effects on free recall within and out of context. Memory 13: 785-795.

27. Miller RB, Brickman SJ (2004) Model of future-oriented motivation and selfregulation. Educational Psychology Review 16: 9-33.

28. Shih CC, Chiang DA, Lai SW, Huc YW (2009) Applying hybrid data mining techniques to web-based self-assessment system of Study and Learning Strategies Inventory. Expert Systems with Applications 36: 5523-5532.

29. Gordon WI (1996) A factor analysis study of the self -regulated learning inventory. Retrieved May 9, 2009.

30. Zhou Y, Graham L, West C (2016) The relationship between study strategies and academic performance. International Journal of Medical Education 7: 324-332.

31. Moghadam MF, Cheraghian B (2009) Study habits and its connection with educational performance in Abadan nursing students. The Journal of Medical Education and Development 1: 21-28.

32. Nourian A, Mousavinasab N, Fahri A, Mohammadzadeh A (2006) Medical students' study skills and habits in Zanjan University of Medical Sciences. Iranian Journal of Medical Education 6: 101-106.

33. Yip MCW (2007) Differences in learning and strategies between high and low achieving university students: A Hong Kong study. Educational Psychology 27: 597-606.

34. Fisher M, King J, Tague G (2001) Development of a self-directed learning readiness scale for nursing education. Nurse Education Today 21: 516-525.

35. Nadi M, Sadjadian I (2011) Validation of a self-directed learning readiness scale for medical and dentistry students. Iranian Journal of Medical Education 11.

36. Hendry GD, Ginns P (2010) Readiness for self-directed learning: validation of a new scale with medical students. Medical Teaching 31: 918-920.
37. Cadorin L, Bressan V, Palese A (2017) Instruments evaluating the self-directed learning abilities among nursing students and nurses: a systematic review of psychometric properties. BMC Medical Education.

38. Borjalilu S, Mojtahedzadeh R, Mohammadi A (2013) Exploring the validity, reliability and factor analysis of self-regulation scale for medical students. Journal of Medical Education and Development 8: 25-35.

39. Karami A, Delawar A, Bahrami H, Karimi Y (2006) Developing a tool for measuring study and learning strategies and determining its relationship with academic achievement. Journal of Psychology 9.

40. Behar-Horenstein LS, Beck DE, Su Y (2018) An initial validation study of the selfrating scale of self-directed learning for pharmacy education. American Journal of Pharmaceutical Education 82: 6251

41. Talebi H, Abedi A, Sadrzadeh O (2014) Construction and validation of students academic motivation scale among Isfahan undergraduates based on self-determination theory. Journal of New Educational Approaches 1: 137-153.

42. Hooman H (2005) Structural equation modeling using LISREL. Tehran: SAMT Publication (in Persian).

43. Hooman H (2018) Structural Equation Modeling with Lisrel Application. Tehran: Samt.

44. Tabachnick BG, Fidell LS (2007) Using multivariate statistics (5thed). New York Allyn and Bacon.

45. Kahn JH (2006) Factor analysis in counseling psychology research, training, an practice: Principle, advances, and application. The Counseling Psychologist 34: 684718

46. Kenny DA (2001) Measuring model fit. New York: Wiley

47. Hailikari T, Nevgi A, Komulainen E (2008) Academic self-beliefs and prior knowledge as predictors of student achievement in mathematics: A structural model. Educational Psychology 28: 59-71.

Copyright: $(2020$ Shabani S. This is an open-access article distributed under the terms of the Creative Commons Attribution License, which permits unrestricted use, distribution, and reproduction in any medium, provided the original author and source are credited. 